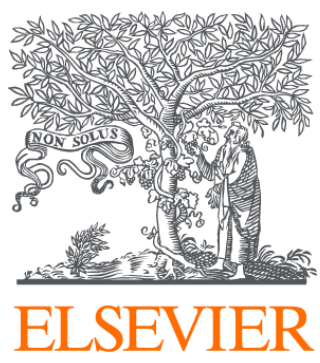

Since January 2020 Elsevier has created a COVID-19 resource centre with free information in English and Mandarin on the novel coronavirus COVID-

19. The COVID-19 resource centre is hosted on Elsevier Connect, the company's public news and information website.

Elsevier hereby grants permission to make all its COVID-19-related research that is available on the COVID-19 resource centre - including this research content - immediately available in PubMed Central and other publicly funded repositories, such as the WHO COVID database with rights for unrestricted research re-use and analyses in any form or by any means with acknowledgement of the original source. These permissions are granted for free by Elsevier for as long as the COVID-19 resource centre remains active. 


\title{
Arguments Against Corticosteroids in Community Acquired Pneumonia
}

\section{Corticoides en la neumonía adquirida en la comunidad. Argumentos en contra}

\author{
Felipe Rodríguez de Castro, ${ }^{\mathrm{a}, *}$ Jordi Solé-Violán ${ }^{\mathrm{b}}$ \\ aServicio de Neumología, Hospital Universitario de Gran Canaria Dr. Negrín, Facultad de Ciencias de la Salud, Universidad de Las Palmas de Gran Canaria, Las Palmas de Gran Canaria, \\ Spain \\ ${ }^{\mathrm{b}}$ Servicio de Medicina Intensiva, Hospital Universitario de Gran Canaria Dr. Negrín, Facultad de Ciencias de la Salud, Universidad de Las Palmas de Gran Canaria, Las Palmas de Gran \\ Canaria, Spain
}

Community-acquired pneumonia (CAP) is the most frequent origin of severe sepsis and the main cause of death by infection in developed countries. In addition, in children under the age of five, it is responsible for two million deaths per year throughout the world, which is more than HIV/AIDS, measles and malaria together. Despite the advances in antimicrobial therapy, this mortality rate has varied little in the last four decades.,2 The evolution of a respiratory infection depends basically on the size of the inoculum, the virulence of the causal microorganism and the inflammatory response of the lung. A small, less aggressive inoculum permits an effective defense with mechanisms of innate immunity. Contrarily, if the microorganisms that reach the lung are numerous or very virulent, an inflammatory response will be triggered, which, although reinforcing innate immunity and being essential for destroying the microorganisms responsible for the infection, also directly contributes to lung damage and alterations in lung function. ${ }^{3}$ The poor evolution of pneumonia is related to an uncontrolled systemic inflammatory response. ${ }^{4}$ It has been confirmed in different studies ${ }^{5-7}$ that, in patients with CAP, the high levels of cortisol are good predictors of mortality, comparable with the pneumonia severity index (PSI). For this reason, in recent years there has been growing interest in the study of the hypothalamic-pituitary-adrenal (HPA) axis, whose activation in situations of stress increase the secretion of cortisol and protect the organism against an excessive inflammatory response. In some severe patients, the intracellular anti-inflammatory activity of the corticosteroids (CS) can be inadequate when compared with the severity of the inflammatory process, coining the phrase "critical illness-related corticosteroid insufficiency (CIRCI)", which is a phenomenon caused by a decrease in the secretion of CS by the suprarenal cortex and/or by the appearance of tissue resistence. ${ }^{8}$ Relative or absolute CIRCI can also occur, although more rarely, in less severe CAP, whose significance is still insufficiently clear.

\footnotetext{
*Corresponding author.

E-mail address: frodcasw@gobiernodecanarias.org (F. Rodríguez de Castro).
}

Despite the rationale behind it, the use of CS in treating pneumonia is very controversial and there are very few clinical studies that have evaluated the intensity of the systemic inflammatory response and the function of the HPA axis in this disease. Theoretically, CS could be beneficial for their anti-inflammatory effect, both genomic and nongenomic; for the role that bronchospasm may have under certain circumstances, either due to the concomitant disease of the patient or because it is induced by the causal agent; and for its stimulator effect on the components of the immune system, such as the expression of TLR in certain cell lines and the increase in the levels of proteins $A$ and $D$ of the surfactant.

The clearest evidence in favor of the use of CS in CAP comes from the analysis of patient cohorts with pneumonia of infrequent etiology, especially Pneumocystis jiroveci. It has been proven in randomized and controlled studies that CS reduce mortality in patients with AIDS, pneumonia by $P$. jiroveci and respiratory insufficiency when administered before or simultaneously with the start of antimicrobial treatment. In a systematic review by Briel et al, ${ }^{9}$ these authors found six studies, with a limited number of patients, that demonstrate a decrease in mortality at 30 days (RR: $0.56 ; 95 \% \mathrm{CI}: 0.32-0.98$ ) as well as after three or four months of follow-up (RR: 0.68 ; $95 \%$ CI: 0.50 0.94), in the patients treated with CS. In three of these studies, it was also found that the need for mechanical ventilation was reduced in the group of patients that received CS (RR: 0.38; 95\% CI: 0.20-0.73). There are no well-designed, controlled, randomized studies evaluating the role of CS in viral pneumonia, although in studies with small cohorts and in several clinical cases CS has been reported to improve the evolution of severe pneumonia caused by Varicella. ${ }^{10}$ It has also been demonstrated that there is a beneficial effect of steroid treatment in patients with severe acute respiratory syndrome (SARS) and low index of oxygenation. ${ }^{11}$ Finally, CS have been successfully used in severe fungal pneumonia, especially in histoplasmosis and blastomycosis. ${ }^{12,13}$

The information available about the use of CS in CAP with standard etiology is even more limited. In 1956, the first published study appeared ${ }^{14}$ reporting encouraging results with the use of hydrocortisone in patients with pneumococcal pneumonia. However, despite 
observing that fever disappeared and symptoms improved faster in patients receiving CS, the authors could not demonstrate lower mortality, fewer complications, or a faster resolution of the clinical or radiological symptoms when compared with those receiving placebo. In fact, it should be highlighted that, in this series, one-third of the patients treated with CS had recurring fever once the treatment with hydrocortisone was suspended, which has also been confirmed in more recent studies. Several decades later, Marik et al carried out a study including 30 adults with severe CAP that was prospective, randomized and placebo-controlled on the effect of a single dose of $10 \mathrm{mg} / \mathrm{kg}$ of hydrocortisone administered half an hour before initiating antibiotherapy.$^{15}$ No evidence was found of a detectable effect in the production of tumor necrosis factor (TNF) in the 12 hours following the administration of the antimicrobials, or in the clinical course of the patients. Some years later, Montón et al determined the level of cytokines in serum and in bronchoalveolar lavage (BAL) in 20 ventilated patients with nosocomial pneumonia and CAP. ${ }^{16}$ The 11 patients that received CS randomly, had significantly lower levels of TNF, interleukin (IL)-1 $\beta$, IL-6 and C-reactive protein (CRP), both in serum as well as in BAL. There was also an observed non-significant tendency towards lower mortality in the group that received CS (36 vs $67 \%$ ). In another randomized, double-blind, placebo-controlled clinical study, Confalonieri et al analyzed the effect of $200 \mathrm{mg}$ of intravenous hydrocortisone, followed by a continuous perfusion of $10 \mathrm{mg} / \mathrm{hour}$ administered for seven days, in a small group of patients with severe CAP hospitalized in an ICU. ${ }^{17}$ The assay had to be suspended when an intermediate analysis revealed a statistically significant improvement in the $\mathrm{PO}_{2} / \mathrm{FiO}_{2}$ ratio $(\mathrm{p}=0.002)$ and in the mortality rate $(0 \mathrm{vs} 30 \%)$ in the patients treated with hydrocortisone. Very favorable results were also observed in the patients that received CS regarding the development of multiorgan dysfunction and late septic shock, as well as in the reduction of the levels of CRP and in the length of hospital stay. However, these results are questionable because the marked difference in mortality observed between the groups was due to deaths after the eighth day and to the high incidence of late septic shock episodes, which has never been observed in other severe CAP studies. It is also striking that, despite the duration of the study and the participation of six hospital centers, only 46 patients were included in the assay and, although there is no statistically significant difference regarding the proportion of patients that received mechanical ventilation in one or the other group, those who were treated with CS were managed with non-invasive ventilation with a greater probability than in the other group. In this sense, readers should be reminded that these same researchers had demonstrated in a previous study a decrease in the mortality in patients with CAP who received noninvasive mechanical ventilation compared with those who were intubated. ${ }^{18}$ All these data, together with the eye-catching absence of deaths in the group of patients receiving treatment with hydrocortisone, raise doubts about the adequate selection and assignation of the patients to each group and suggest the existence of a significant baseline difference between them in terms of risk of death, which seriously questions the findings.

In another prospective, randomized and open study, Mikami et $\mathrm{al}^{19}$ affirmed that the administration of $40 \mathrm{mg} / 24$ hours of prednisolone for three days in hospitalized patients with CAP (55\% with PSI of IV or V), did not shorten the hospitalization, which was the primary objective of the assay. García-Vidal et al ${ }^{20}$ carried out an observational, retrospective study of a cohort of 308 patients with severe CAP. Seventy of these patients (23\%) received, in addition to antimicrobial agents, CS in variable doses and durations, almost always due to bronchospasm in the context of previously-diagnosed chronic obstructive pulmonary disease (COPD). In the multivariate analysis, the authors found that those patients who were administered CS had less mortality (OR: 0.28; 95\% CI: 0.11-0.73). In any event, it is a retrospective study in which the administration of CS had varying dosages and durations and at different evolutionary moments of the disease, which is a relevant aspect as the inflammatory response in CAP is a dynamic process. It is also surprising that the overall mortality of this series was less than that expected for the PSI of the cohort. The multicenter CORTICUS study also did not demonstrate an overall benefit of the treatment with CS in patients with septic shock. ${ }^{21}$ In this study, $37 \%$ of the subjects included had pneumonia, and no benefit could be found in these either. Consistent with these findings, it has been found that when severe CAP presents high serum levels of cortisol (> $25.7 \mu \mathrm{g} / \mathrm{dL}$ ), it is associated with mortality, contrary to what happens when an inadequate response is observed in the stimulation test with corticotrophin. ${ }^{22}$

Recently, the first double-blind, placebo-controlled clinical assay was published, including patients hospitalized with CAP with varying degrees of severity. ${ }^{23}$ In this study, the most extensive with these characteristics published to date, 213 patients randomly received either $40 \mathrm{mg}$ of prednisolone in one daily dose for 7 days or placebo, in addition to the corresponding antimicrobial treatment, except for macrolides. Excluded were patients who previously needed steroids, which certainly conditioned an underrepresentation of some concomitant diseases, such as COPD. The primary objective was to analyze the clinical cure rate on the seventh day, defined as either the resolution or improvement of symptoms with no need for additional therapy, which can suppose a bias inherent to all subjective variables. The secondary objectives were the clinical cure rate at 30 days, the duration of the hospital stay, the time necessary to reach clinical stability and the reduction of CPR. No significant differences could be demonstrated between the groups for any of the objectives proposed, neither in the overall group nor when the most severe groups were analyzed separately. Nevertheless, in the patients that received CS, more late failures were observed (recurrence of the symptoms and signs of pneumonia after 72 hours of hospitalization and after an initial improvement), especially in less severe pneumonia (OR: 2.35; 95\% CI; 1.00-5.53). This finding confirms the recommendations to withdraw CS slowly in order to avoid the hemodynamic and immunologic rebound due to the increase in proinflammatory mediators when their specific receptors are still suppressed. It was also observed that the cure rate in pneumococcal pneumonia was statistically greater in the placebo group..$^{24}$

In summary, and despite the theoretical potential benefits, the evidence that is currently available does not allow for the systemic administration of CS to be recommended in hospitalized patients with CAP. The majority of the studies are very limited in size, present unacceptable biases or their designs do not provide conclusions on which strong recommendations can be based. New controlled, randomized, clinical assays with larger sample sizes are needed to evaluate the adrenal function and to definitively and clearly establish the risks and the benefits for using CS in patients with CAP. ${ }^{25}$ Until the results are published of new studies that are already in progress, ${ }^{24}$ it seems reasonable to think that some patients could benefit from the use of CS, such as patients with CAP of certain etiologies, those with adrenal insufficiency, those with asthma or COPD or those who develop septic shock with a poor response to the resuscitation maneuvers with liquids and perfusion of pressor amines. ${ }^{26,27}$

\section{References}

1. Mortensen EM, Coley C, Singer DE, Marrie TJ, Obrosky DS, Kapoor WN, et al. Causes of death for patients with community-acquired pneumonia: results from the pneumonia patient outcomes research team cohort study. Arch Intern Med. 2002;162:1059-64.

2. Menéndez R, Torres A, Aspa J, Capelastegui A, Prat C, Rodríguez de Castro F. Neumonía adquirida en la comunidad. Nueva normativa de la Sociedad Española de Neumología y Cirugía Torácica (SEPAR). Arch Bronconeumol. 2010;46:543-58.

3. Solé J, Marcos A, Aspa J, Rodríguez de Castro F. Corticosteroids and communityacquired pneumonia. Clin Pulm Med. 2003;10:255-62.

4. Kellum JA, Kong L, Fink MP, Weissfeld LA, Yealy DM, Pinsky MR, et al. Understanding the inflammatory cytokine response in pneumonia and sepsis: results of the Genetic and Inflammatory Markers of Sepsis (GENIMS) Study. Arch Intern Med. 2007;167:1655-63. 
5. Christ-Crain M, Stolz D, Jutla S, Couppis O, Müller C, Bingisser R, et al. Free and total cortisol levels as predictors of severity and outcome in community-acquired pneumonia. Am J Respir Crit Care Med. 2007;176:913-20.

6. Gotoh S, Nishimura N, Takahashi O, Shiratsuka $\mathrm{H}$, Horinouchi $\mathrm{H}$, Ono $\mathrm{H}$, et al. Adrenal function in patients with community-acquired pneumonia. Eur Respir J. 2008;31:1268-73.

7. Kolditz M, Halank M, Schulte-Hubbert B, Höffken G. Adrenal function is related to prognosis in moderate community-acquired pneumonia. Eur Respir J. 2010;36: 615-21.

8. Annane D, Meduri G, Marik P. Critical illness-related corticosteroid insufficiency and community-acquired pneumonia: back to the future! Eur Respir J. 2008;31:1150-2

9. Briel M, Bucher HC, Boscacci R, Furrer H. Adjunctive corticosteroids for Pneumocystis jiroveci pneumonia in patients with HIV-infection. Cochrane Database Syst Rev. 2006;3:CD006150.

10. Adhami N, Arabi Y, Raees A, Al-Shimemeri A, Ur-Rahman M, Memish ZA. Effect of corticosteroids on adult varicella pneumonia: cohort study and literature review. Respirology. 2006;11:437-41.

11. Cheng RC, Tang XP, Tan SY, Liang BL, Wan ZY, Fang JQ et al. Treatment of Severe Acute Respiratory Syndrome with glucoesteroids. The Guangzhou experience. Chest. 2006;129:1441-52.

12. Goldman M, Johnson PC, Sarosi GA. Fungal pneumonias: the endemic mycoses. Clin Chest Med. 1999;20:507-19.

13. Lahm T, Neese S, Thornburg AT, Ober MD, Sarosi GA, Hage CA. Corticosteroids for blastomycosis-induced ARDS: a report of two patients and review of the literature. Chest. 2008;133:1478-80.

14. Wagner HN, Bennet IL, Lasagna L, Cluff LE, Rosenthal MB, Mirick GS. The effect of hydrocortisone upon the course of pneumococcal pneumonia treated with penicillin. Bull Johns Hopkins Hosp. 1956;98:197-215.

15. Marik P, Kraus P, Sribante J, Havlik I, Lipman J, Johnson DW. Hydrocortisone and tumor necrosis factor in severe community-acquired pneumonia: a randomized controlled study. Chest. 1993;104:389-492.

16. Montón C, Ewig S, Torres A, El-Ebiary M, Fililla X, Rañó A, et al. Role of glucocorticoids on inflammatory response in nonimmunosuppressed patients with pneumonia: a pilot study. Eur Respir J. 1999;14:218-20.
17. Confalonieri M, Urbino R, Potena A, Piatella M, Parigi P, Puccio G, et al. Hydrocortisone infusion for severe community-acquired pneumonia: a preliminary randomized study. Am J Respir Crit Care Med. 2005;171:242-8.

18. Confalonieri M, Potena A, Carbone G, Porta RD, Tolley EA, Meduri GU. Acute respiratory failure in patients with severe community-acquired pneumonia. A prospective randomized evaluation of noninvasive ventilation. Am J Respir Crit Care Med. 1999;160:1585-91.

19. Mikami M, Suzuki M, Kitagawa H, Kawakami M, Hirota N, Yamaguchi H, et al. Efficacy of corticosteroids in the treatment of community-acquired pneumonia requiring hospitalization. Lung. 2007;185:249-55.

20. García-Vidal C, Calbo E, Pascual V, Ferrer C, Quintana S, Garau J. Effects of systemic steroids in patients with severe community-acquired pneumonia. Eur Respir J. 2007;30:951-6.

21. Sprung CL, Annane D, Keh D, Moreno R, Singer M, Freivogel K, et al. Hydrocortisone therapy for patients with septic shock. N Engl J Med. 2008;358:111-24.

22. Salluh JI, Bozza FA, Soares M, Verdeal JC, Castro-Faria-Neto HC, Lapa e Silva JR, et al. Adrenal response in severe community-acquired pneumonia: impact on outcomes and disease severity. Chest. 2008;134:947-54.

23. Snijders D, Daniels J, De Graaf C, Van der Werf TS, Boersma WG. Efficacy of corticosteroids in community-acquired pneumonia. A randomized double-blinded clinical trial. Am J Respir Crit Care Med. 2010; 181:975-82.

24. Meduri GU, Bell WA, Confalonieri M. Glucocorticoid treatment in communityacquired pneumonia without severe sepsis. No evidence of efficacy. Am J Respir Crit Care Med. 2010;181:975-82.

25. Agustí C, Torres A. Respuesta inflamatoria en la neumonía: ¿son útiles los glucocorticoides? Arch Bronconeumol. 2003;39:143-5.

26. Marik PE, Pastores SM, Annane D, Meduri GU, Sprung CL, Arlt W, et al. Recommendations for the diagnosis and management of corticosteroid insufficiency in critically adult patients: consensus statements from an international task force by the American College of Critical Care Medicine. Crit Care Med. 2008;36:1937-49.

27. Dellinger RP, Levy MM, Carlet JM, Bion J, Parker MM, Jaeschke R, et al. Surviving Sepsis Campaign: International guidelines for management of severe sepsis and septic shock 2008. Crit Care Med. 2008;36:296-327. 